\title{
A morte, o sofrimento e a doença - um luto diferente
}

Tânia Dias, ${ }^{1}$ Nunes de Sousa ${ }^{2}$

\section{RESUMO}

Introdução: São competências do Médico de Família (MF) a gestão dos problemas de saúde em todas as suas dimensões e a utilização eficiente dos recursos de saúde num papel de provedoria do doente.

Descrição do Caso: Homem de 51 anos, casado, pai de 3 filhos vivos. Os antecedentes patológicos iniciaram-se em 2008, com uma perturbação depressiva reativa à morte de um filho. Em 2011 inicia «convulsões», atribuindo-se-lhe o diagnóstico, em neurologia, de epilepsia, tendo sido medicado com doses crescentes de anticonvulsivantes apesar de estudo etiológico inconclusivo. Em agosto de 2012, após intoxicação medicamentosa voluntária (referindo «...eu tenho de ir para a beira do menino...»), é referenciado à consulta de psiquiatria que nunca se concretizou. Em março de 2013, na consulta do MF, dada a persistência da sintomatologia, considera-se que poderá existir um quadro de somatização/conversão, sendo o doente referenciado à consulta de psiquiatria. É observado em abril de 2013, medicado com sertralina e clonazepam, com resolução parcial das «crises».

Comentário: Este caso salienta a importância da valorização das queixas no contexto biopsicossocial do doente. A perda de um membro da família está associada a uma maior vulnerabilidade a distúrbios psiquiátricos, nomeadamente comportamentos suicidas. Ressalta o papel do MF como gestor dos recursos de saúde e orientador do paciente. Numa era de subespecialização, é função do Médico de Família oferecer ao doente uma abordagem holística, valorizando tanto o seu sofrimento como a sua doença.

Palavras-chave (DeCS): Pesar; Transtorno Conversivo; Saúde Holística.

\section{INTRODUÇÃO}

1 definição da WONCA ${ }^{1}$ para a disciplina de medicina geral e familiar (MGF) e as competências do médico de família (MF) estabelece os princípios pelos quais se deve reger a prática destes profissionais.

O MF deve desenvolver uma abordagem centrada na pessoa, orientada para o indivíduo, a sua família e a sua comunidade, uma vez que a MGF lida com as pessoas e os seus problemas no contexto das suas circunstâncias de vida e não como patologias ou «casos» impessoais. Tem a competência de gerir, simultaneamente, os problemas de saúde tanto agudos como crónicos, lidando com estes quer na dimensão física e psicológica quer na dimensão social, cultural e existencial. Deve reconhecer todas estas dimensões simultanea-

Médica Interna de Medicina Geral e Familiar, USF Famílias, Lourosa, Santa Maria da Feira.

${ }^{2}$ Assistente Graduado Sénior de Medicina Geral e Familiar e Orientador de Formação, USF Famílias, Lourosa, Santa Maria da Feira. mente, atribuindo um peso específico apropriado a cada uma delas. O comportamento e os padrões de doença variam em função de muitas destas questões, podendo estar na origem de grande sofrimento aquelas intervenções que não considerem a raiz do problema segundo o doente.

Por último, o MF tem o compromisso de utilizar eficientemente os recursos de saúde, coordenando a prestação de cuidados, trabalhando com outros profissionais no contexto dos cuidados de saúde primários e gerindo a interface com outras especialidades, assumindo um papel de provedoria do doente sempre que necessário. ${ }^{1}$

O relato de caso que se apresenta de seguida reflete a importância da abordagem holística do doente que procura o seu MF durante um período de crise na sua vida. É seu objetivo salientar que o sofrimento pode ser causa suficiente para a ocorrência de patologia, orgânica ou não, perturbando a qualidade de vida do paciente. 


\section{DESCRIÇÃO DO CASO}

\section{Identificação}

Homem de 51 anos, raça caucasiana, terceiro ano de escolaridade, corticeiro de profissão, desempregado desde 2007, altura em que teve de abandonar o trabalho para se tornar cuidador de um dos filhos, com doença oncológica. Casado, integrava um agregado familiar nuclear, constituído por cinco pessoas (o doente, a esposa e três filhos, com 23, 18 e 9 anos), no estadio VI do ciclo de Duvall (apesar de, devido às circunstâncias familiares, ainda desempenhar papéis dos estadios IV e V), pertencente à classe média baixa de Graffar. Tratava-se de uma pessoa crente, católica, frequentando com regularidade a igreja, bem como a sepultura do filho. Apresentava hábitos tabágicos (carga tabágica de 20UMA) e negava hábitos etílicos. Dos antecedentes pessoais, de realçar osteoartrose do joelho esquerdo, ombro doloroso por tenossinovite com rotura à direita (cirurgia em 2012), perturbação depressiva e epilepsia.

Como antecedentes familiares, salientam-se fatores de risco cardiovasculares (hipertensão arterial e diabetes mellitus tipo 2) e doença pulmonar obstrutiva crónica.

\section{A consulta-chave...}

Em março de 2013, o doente recorreu à consulta do seu MF, acompanhado por uma vizinha, por «ataques epiléticos» frequentes. A descrição que os dois faziam das crises era algo atípica. O doente «espuma da boca, grita, bate com os pés no chão, anda sem rumo», mas nunca teve incontinência de esfíncteres nem mordedura de língua, ficando, após a crise, «desmaiado» cerca de quinze minutos, respondendo, contudo, aos estímulos verbais. Segundo os dados do processo clínico, foi diagnosticado com epilepsia dois anos antes, mantendo seguimento em neurologia, medicado com carbamazepina 400mg 3id e fenitoína 100mg 2id, sem controlo completo das crises.

Perante esta descrição e o tratamento em dose quase máxima de anticonvulsivantes, considerou-se que as queixas poderiam não ser completamente explicadas pela epilepsia e que poderia existir associado um quadro de somatização/conversão. Por este motivo efetuou-se referenciação para consulta externa de psiquiatria.

Nesta história clínica surgiam três critérios de Janet-
-Christie-Seely² (sintomas inespecíficos, doença crónica e resistência ao tratamento) que conduziram ao estudo deste doente com recurso à avaliação familiar e à análise da sua história pessoal.

\section{Avaliação familiar}

Foi realizada uma entrevista ao doente com a presença da esposa, à qual também se recorreu conforme necessário.

Como se verifica na representação do genograma familiar e como já foi referido na identificação do doente, este pertencia a um agregado familiar nuclear de cinco elementos (Figura 1). De salientar a morte do terceiro filho, em 2008, com oito anos, por doença oncológica com dois anos de evolução.

A esposa, empregada fabril na indústria corticeira, era a única fonte de rendimentos da família, assumindo o tradicional papel de "chefe de família», situação que, se foi tolerada durante a doença do filho até à sua morte, constituía uma inversão de papéis que contribuía para a instabilidade do agregado familiar.

Segundo o doente e a esposa, os filhos apresentavam algum ressentimento pela situação protagonizada pelo irmão falecido, na altura cuidado principalmente pelo pai, facto que se refletia na relação conflituosa do doente com o primeiro filho (Figura 1). Este último tinha saído de casa há cerca de 3 anos, tendo, contudo, regressado devido a insuficiência económica. Este facto era também uma fonte de conflito com o doente. A filha encontrava-se a terminar o ciclo secundário e assumia um papel de apoio nas tarefas em casa. O filho mais novo frequentava o ensino básico e constituía um fator importante de apoio a este doente devido à excelente relação entre os dois (acompanhava-o nas atividades religiosas e nas idas à sepultura do filho).

Verificou-se que este doente assumia um papel de dependência, criando um importante fator de stress na família. Devido à ocorrência das crises, considerava-se impossibilitado de trabalhar, passando os dias «fechado em casa», o que contribuía para o agravamento das suas queixas de humor deprimido.

Quando se pediu ao doente para realizar uma representação da sua família e recursos em caso de necessidade, através do círculo familiar de Thrower, verificou-se novamente o maior afastamento em relação ao primeiro filho (Figura 2). O doente referia encontrar-se 


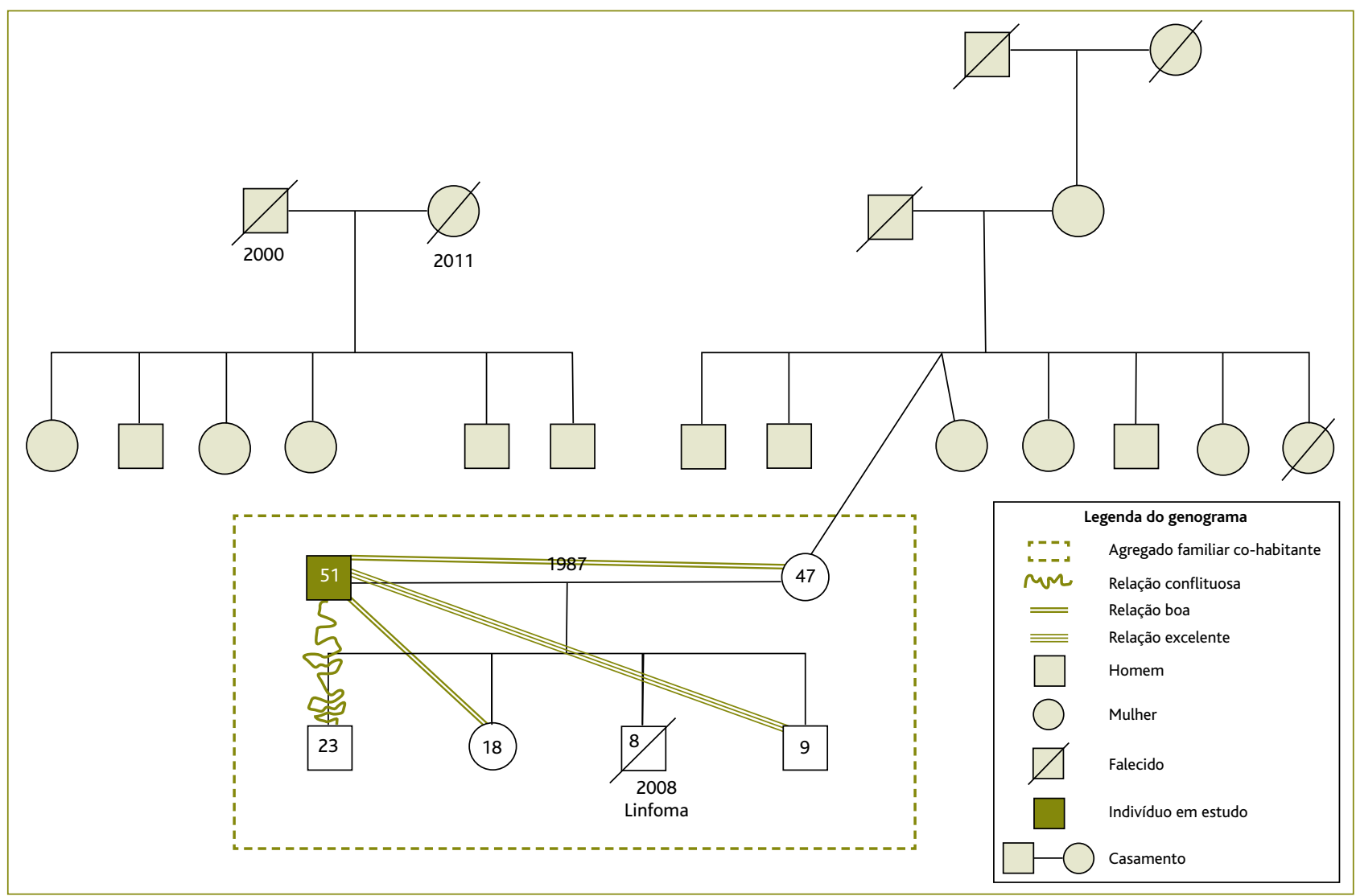

Figura 1. Genograma familiar com Psicofigura de Mitchell (02/05/2013)

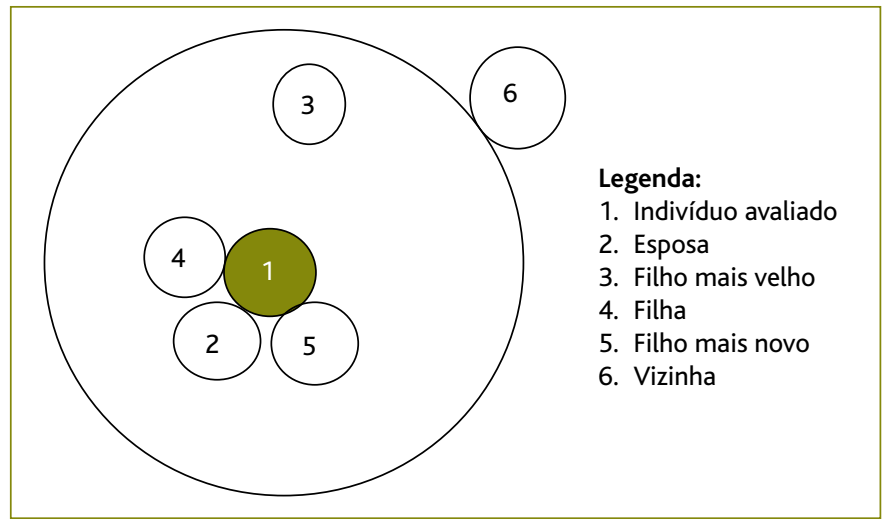

Figura 2. Círculo familiar de Thrower (02/05/2013)

relativamente satisfeito com a sua representação da família e em caso de necessidade recorrer à esposa ou à vizinha. De salientar a importância desta última como elemento de apoio da família: como já referido anteriormente, a esposa do doente era a única fonte de ren- dimento familiar, o que a impedia de acompanhar o doente sempre que necessário.

O doente apresentava um Apgar familiar de cinco, correspondendo a uma disfunção familiar moderada (Quadro I). Estava descontente, sobretudo no âmbito da comunicação familiar, «sente que não é ouvido e que a família não partilha consigo decisões importantes».

Analisando a linha de vida de Medalie, constatouse que os principais problemas que afetavam este indivíduo, nomeadamente a perturbação depressiva, a epilepsia e a intoxicação medicamentosa voluntária (referida adiante), apenas se manifestaram após a morte do filho (Quadro II). Quando se confrontou o doente com esta constatação, pareceu compreender que o sofrimento, consequente à morte do filho, poderá ter estado na origem de todo o quadro que desenvolveu desde 2008, facto que até então não tinha considerado. 


\section{QUADRO I. Apgar familiar de Smilkstein (02/05/2013)}

Apgar familiar de Smilkstein

\begin{tabular}{|c|c|c|c|c|}
\hline \multicolumn{2}{|r|}{ Apgar familiar de Smilkstein } & Sempre (2) & Às vezes (1) & Nunca (0) \\
\hline Adaptação & $\begin{array}{l}\text { Estou satisfeito com a ajuda que recebo da minha família sempre que } \\
\text { alguma coisa me preocupa. }\end{array}$ & & $x$ & \\
\hline Comunicação & $\begin{array}{l}\text { Estou satisfeito pela forma como a minha família discute assuntos } \\
\text { de interesse comum e partilha comigo a solução do problema. }\end{array}$ & & & $\mathrm{X}$ \\
\hline Crescimento & $\begin{array}{l}\text { Acho que a minha família concorda com o meu desejo de encetar } \\
\text { novas atividades ou de modificar o meu estilo de vida. }\end{array}$ & & $\mathrm{X}$ & \\
\hline Afeto & $\begin{array}{l}\text { Estou satisfeito com o modo como a minha família manifesta a sua } \\
\text { afeição e reage aos meus sentimentos, tais como irritação, pesar e amor. }\end{array}$ & $X$ & & \\
\hline Dedicação & Estou satisfeito com o tempo que passo com a minha família. & & $x$ & \\
\hline
\end{tabular}

Esta pessoa sofreu vários acontecimentos significativos de vida num curto período de tempo: a doença do filho; a perda do seu trabalho com alterações na situação económica da família; a morte do filho com alterações nas atividades sociais da família, que se isolou da restante comunidade e se fechou sobre si própria. Segundo a escala de readaptação social de Holmes e Rahe, o doente, com um total de 179 pontos, tem «Aumento do risco de doença psicossomática».

\section{História pessoal}

Os antecedentes patológicos deste doente iniciaram-se em 2008 quando recorreu pela primeira vez ao MF por insónias, cefaleias e mialgias desde a morte de um filho com oito anos, por doença oncológica, do qual tinha sido o principal cuidador. Nessa altura considerou-se que o doente se encontrava a vivenciar um processo natural de luto e adotaram-se medidas comportamentais, tentando oferecer ao doente estratégias de coping para lidar com o seu sofrimento. Em setembro de 2009, após várias consultas por queixas ortopédicas, volta por persistência das queixas depressivas (insónia e humor deprimido), tendo sido medicado com amitriptilina $25 \mathrm{mg}$ id, que manteve até junho de 2011.

Em setembro de 2011 traz nota de alta do serviço de urgência do hospital de referência, onde foi observado por «crises convulsivas». Teve alta com orientação para a consulta externa de neurologia. Não havia qualquer referência a antecedentes pessoais ou familiares de epilepsia.

Em novembro é novamente observado no serviço de urgência e, segundo o relatório de alta, a família refere que as «crises» têm uma frequência de três por dia desde setembro. Há uma descrição atípica dos eventos: «...estava na rua com a irmã e, de forma súbita, esta viu que estava de pé, de olhos fechados e a efetuar movimentos com a boca; ao ser questionado, não respondia

\begin{tabular}{|l|l|l|}
\hline \multicolumn{2}{|l|}{ QUADRO II. Linha de vida de Medalie } \\
Etapa/Crise & Data & Síndrome \\
\hline Casamento & 1987 & \\
\hline Falecimento do pai & 1992 & Abuso do tabaco \\
\hline $\begin{array}{l}\text { Diagnóstico de linfoma } \\
\text { ao terceiro filho }\end{array}$ & 2000 & \\
\hline $\begin{array}{l}\text { Desemprego/inicia papel de } \\
\text { cuidador do filho }\end{array}$ & 2006 & \\
\hline Falecimento do terceiro filho & 2008 & Perturbação depressiva \\
\hline Falecimento da mãe & 2009 & Osteoartrose do Joelho \\
\hline 2011 & $\begin{array}{l}\text { Epilepsia } \\
\text { Alterações do metabolismo dos lípidos } \\
\text { Neoplasia genital benigna }\end{array}$ \\
\hline
\end{tabular}


e ficou com a boca de lado a 'espumar-se' com desvio do pescoço para a esquerda; mexia ambos os braços e pernas, ainda de pé, até que de forma progressiva as pernas perderam força e caiu...», sem incontinência de esfíncteres, sem mordedura de língua e com duração aproximada de quinze minutos. Colocada a dúvida, crise convulsiva versus crise conversiva, é avaliado em psiquiatria, não sendo valorizado o quadro, tendo alta medicado com magnésio, trazodona e clobazam e com encaminhamento urgente para a consulta externa de neurologia, onde é feito o diagnóstico clínico de epilepsia. O doente efetua estudo etiológico, que se revela inconclusivo (tomografia computorizada, ressonância magnética nuclear, eletroencefalograma e punção lombar, todos normais), sendo acompanhado e medicado com doses crescentes de anticonvulsivantes, sem controlo eficaz da sintomatologia.

Em julho de 2012 é novamente observado no serviço de urgência por «crises convulsivas». Nesta altura é feito o doseamento de fenitoína e detetam-se níveis subterapêuticos, apesar do doente garantir que cumpre a medicação.

Em agosto de 2012 é internado na unidade de cuidados intermédios do hospital de referência por intoxicação medicamentosa voluntária com ideação suicida. Neste internamento é avaliado pela psiquiatria. Questionado sobre a sua motivação para a tentativa de suicídio, refere que já há algum tempo dizia aos familiares: «...eu tenho de ir para a beira do menino...». É referenciado à consulta externa de psiquiatria, não sendo contudo observado, por motivo que se desconhece.

Após a tentativa de suicídio, só volta a recorrer à consulta em março de 2013 - o contacto apresentado no início da descrição.

\section{A resolução...}

Observado na consulta externa de psiquiatria em abril de 2013, foi medicado com sertralina e clonazepam, com diminuição da frequência das «crises».

Num contacto posterior, esporádico, dois meses depois do início da terapêutica antidepressiva, o doente referiu que teve apenas dois episódios de «crise», pouco «aparatosos» e com rápida resolução. Nesta ocasião, o doente aparentava um bom estado geral, encontrando-se muito satisfeito pela diminuição da frequência das «crises» e empenhado na frequência da consulta de psiquiatria e na tentativa de abordagem do seu sofrimento. Mantinha seguimento semestral em neurologia e psiquiatria, estando medicado com carbamazepina 400mg 3id, fenitoína 100mg 2id, sertralina 50mg id e clonazepam $0,5 \mathrm{mg}$ id, até completo esclarecimento etiológico.

O doente referiu que a família se encontrava «mais aliviada» com a melhoria do seu estado de saúde, apesar de ainda existir algum conflito, nomeadamente com o filho mais velho.

No entanto, e apesar da melhoria verificada, mantinham-se as circunstâncias biopsicossociais que o trouxeram inicialmente à consulta. Apenas lhe foram fornecidos alguns recursos para a gestão do seu sofrimento.

\section{COMENTÁRIO}

Não é fácil colocar um «rótulo» a este doente. Poderá apresentar uma epilepsia? Esta doença com início na idade adulta (depois dos 40 anos) é uma entidade rara, sobretudo com estudo analítico e imagiológico normal e sem história familiar. ${ }^{3}$ Poderá tratar-se de uma forma de luto patológico? Todo o quadro principia após a morte do filho, apesar do doente não preencher os critérios diagnósticos. Poderá sofrer de distimia ou perturbação depressiva major? O seu fácies e humor habitual enquadram-se. Poderá manifestar uma perturbação conversiva? Os sintomas e a sua cronologia (início após um evento significativo de vida) poderão ser compatíveis.

Contudo, para os autores, mais importante do que enquadrá-lo numa síndrome será valorizar o Doente em si!

Estava-se perante um doente em sofrimento, com dificuldade em expressá-lo e assim obter apoio. Aparentemente, a única forma que encontrou para o mostrar ao seu médico foi através de sintomas físicos. Inicialmente o doente ofereceu as queixas depressivas, insónia, cefaleias e mialgias. Posteriormente estas queixas tornaram-se mais elaboradas com os episódios de «crise».

É possível, embora pouco provável, que este doente tenha uma epilepsia de início na idade adulta. Após uma primeira avaliação por psiquiatria, que não valorizou o quadro, este doente foi encaminhado para neurologia com o «rótulo» de epilepsia, o que pode ter contribuído para uma abordagem nesta linha. No entanto, 
com um estudo etiológico inconclusivo, a ausência de melhoria com doses crescentes de fármacos anticonvulsivantes e o agravamento do quadro com intoxicação medicamentosa voluntária, a reavaliação do caso e da hipótese diagnóstica deveria prevalecer.

Para ajudar o doente, algo mais foi necessário: a capacidade para o entender, os seus pensamentos, sentimentos e medos, a sua perceção da doença e o impacto desta na sua vida. ${ }^{4}$ Só após a valorização do seu sofrimento e do esclarecimento no seu contexto de vida, gerindo uma colaboração eficiente entre as três especialidades (MGF, psiquiatria e neurologia), foi conseguido um verdadeiro alívio e controlo da doença.

A perda de um membro da família, sobretudo a perda de um filho, tem sido associada a maior vulnerabilidade a distúrbios psiquiátricos, fortemente associados a comportamentos suicidas, ${ }^{5}$ nomeadamente o distúrbio conversivo. Este, sendo um tipo de transtorno somatoforme, envolve sintomas ou défices da função sensitiva ou motora voluntária que sugerem uma condição neurológica ou médica orgânica, mas não conseguem ser totalmente explicados por esta. Após uma avaliação cuidadosa com exame neurológico, exames de imagem e analíticos inconclusivos, não é encontrada explicação orgânica para os sintomas (Quadro III).$^{6-7}$ As convulsões não-epiléticas psicogénicas (psychogenic nonepileptic seizures, PNES) são um sintoma clássico de transtorno conversivo. Esta perturbação apresenta uma incidência anual de 22 casos por 100.000 habitantes por ano e existe um rácio mulher para homem de 2-10:1. Contudo, os homens são responsáveis por $40 \%$ das PNES. A idade típica de início situa-se entre a segunda e a quarta década de vida; porém, podem ocorrer casos desde a infância até à nona década. ${ }^{5-6}$ É mais comum em populações rurais, em indivíduos com baixo status socioeconómico e nível de escolaridade e reduzida «sofisticação psicológica».

Este caso salienta a importância da valorização das queixas e da sua interpretação no contexto biopsicossocial do doente. ${ }^{8}$ É precisamente esta competência que dá destaque ao MF, pela sua capacidade de abordar não só o doente como toda a sua envolvência.

O sofrimento, tido na maioria das vezes como consequência da doença, suporta neste caso uma inversão de papéis e torna-se a sua causa. Pode considerar-se que, nesta história, ocorre uma mudança de paradig-

\begin{tabular}{l} 
QUADRO III. Critérios de diagnóstico DSM-IV \\
para Perturbação Conversiva \\
(adaptado de Marques-Teixeira J. ${ }^{6}$ ) \\
Critérios de Diagnóstico DSM-IV para Perturbação \\
Conversiva \\
\hline Um ou mais sintomas ou défice que afetam funções \\
motoras voluntárias ou sensoriais que se parecem com um \\
quadro neurológico ou médico \\
Existência de fatores psicológicos associados com o sintoma \\
que precedem a sua aparição \\
\hline O sintoma ou défice não é intencional nem simulado \\
\hline Os sintomas ou défices não podem ser explicados, após \\
estudos físicos ou laboratoriais adequados, como efeitos de \\
um quadro médico, do uso de substâncias, ou como uma \\
experiência ou conduta culturalmente sancionadas \\
\hline O sintoma ou défice produz danos ou incapacidades \\
significativas no funcionamento social, ocupacional ou de \\
outra índole \\
\hline O sintoma ou défice não se limita a dor ou disfunção sexual, \\
não ocorre como parte de uma perturbação de somatização \\
e não é explicável por outra perturbação mental
\end{tabular}

ma: sendo habitual na medicina tratar a doença como forma de resolver o sofrimento, nesta situação tornou-se necessário minorar o sofrimento de maneira a tratar o doente. Neste paciente em particular, a única estratégia de coping baseou-se nas suas crenças religiosas, que valorizam o sofrimento como meio de obter o perdão e a redenção, mas que se revelaram ineficazes perante a perda do seu filho. A solução encontrada na consulta de MGF consistiu na valorização do sofrimento do doente e na referenciação à consulta de psiquiatria de forma a oferecer estratégias de coping alternativas.

Este caso ressalta assim o valor do MF como gestor dos recursos de saúde e pilar na negociação do plano terapêutico com o doente.

O que fazer então «depois da morte...»?

É importante prestar atenção aos processos de luto, avaliando se os doentes adquiriram estratégias de $\mathrm{co}$ ping, e permitir e incentivar o doente a expressar o seu sofrimento. É compreensível que, em determinadas circunstâncias, a capacidade para aceitar a perda seja particularmente difícil. Contudo, estudos sugerem que ní- 
veis mais elevados de aceitação parecem estar associados a menor sofrimento, implicando benefício na promoção da mesma. ${ }^{9-10}$

É também necessário prestar atenção às queixas recorrentes e inespecíficas e, sobretudo, às «anormalidades diagnósticas» quando, na tentativa de esclarecer estes quadros, se medicaliza e se realizam exames diagnósticos desnecessários sucessivamente normais.

Numa era de subespecialização, é cada vez mais função do MF conseguir «dar um passo atrás», ver o doente como um todo, integrado num sistema familiar e social.

É objetivo principal do MF oferecer uma abordagem holística ao doente, considerando a doença, o seu contexto mas, sobretudo, o seu sofrimento.

\section{REFERÊNCIAS BIBLIOGRÁFICAS}

1. WONCA Europa.A definição europeia de medicina geral e familiar. Lisboa: APMGF; 2012.

2. Christie-Seely J, Talbot $Y$. The contrast between working with families and family therapy. In Christie-Seely J, editor. Working with the family in primary care: a systems approach to health and illness. New York: Praeger; 1984. p. 258- 65.

3. Duncan JS, Sander JW, Sisodiya SM, Walker MC. Adult epilepsy. Lancet. 2006;367:1087-100.

4. McWhinney IR, Freeman T. Manual de medicina de família e comunidade. $3^{\mathrm{a}}$ ed. Porto Alegre: Artmed; 2010.

5. Meert KL, Shear K, Newth CJL, Harrison R, Berger J, Zimmerman J, et al. Follow-up study of complicated grief among parents eighteen months after a child's death in the pediatric intensive care unit. J Palliat Med. 2011;14(2):207-14.

6. Medscape. Conversion disorders. Medscape; 2013 [cited 2013 Jun 8]. Available from: http://emedicine.medscape.com/article/287464overview\#showall

7. Marques-Teixeira J. Consensos psiquiátricos: manual prático para clínicos gerais. Linda-a-Velha: Vale \& Vale Editores; 2007.

8. Engel GL. The clinical application of the biopsychosocial model. Am J Psychiatry. 1980;137(5):535-44.

9. Prigerson HG, Maciejewski PK. Grief and acceptance as opposite sides of the same coin: setting a research agenda to study peaceful acceptance of loss. Br J Psychiatry. 2008;193(6):435-7.

10. Borins M. Grief counseling. Can Fam Physician. 1995;41:1207-11.

\section{CONFLITOS DE INTERESSE}

Os autores declaram não ter conflito de interesses.

\section{ENDEREÇO PARA CORRESPONDÊNCIA \\ Tânia Dias \\ Endereço postal: Rua Fundo da Gandra n. ${ }^{\circ} 601^{\circ}$ nascente \\ 3730-255 Vale de Cambra \\ E-mail: taniadmdias@gmail.com}

Recebido em 03-08-2013

Aceite para publicação em 23-03-2014

Artigo escrito ao abrigo do novo acordo ortográfico.

\section{ABSTRACT}

\section{DEATH, SUFFERING AND DISEASE - A DIFFERENT KIND OF GRIEF}

Introduction: The Family Physician should have the ability to manage health problems in all their dimensions and use health resources efficiently as the patient's advocate.

Case Description: This report describes a 51 year-old man who was married and the father of three living children. His symptoms began in 2008 following the death of his son and an episode of reactive depression. In 2011 he had his first "seizure". He consulted with a neurologist who diagnosed epilepsy and prescribed anticonvulsants in progressively increasing doses despite inconclusive investigations. In August 2012, he attempted suicide with a drug overdose saying "... I want to be near the boy." He was then referred, for the first time, to a psychiatrist. In March 2013, he was re-evaluated by his family physician, because of the persistence of the symptoms. He was diagnosed with somatization/conversion and was again referred for psychiatric consultation. He was treated with sertraline and clonazepam, which contributed to the partial resolution of the "seizures".

Comment: This case emphasizes the importance of assessing all of the patient's health issues in the biopsychosocial context. The loss of a family member is associated with increased vulnerability to develop psychiatric disorders, including suicidal behavior. It emphasizes the role of the family physician, who has the tools to manage health resources and the ability to guide the patient. In an era of sub-specialization, it is important that the family physician has the ability to use a holistic approach, focusing on suffering as well as the disease.

Keywords (MeSH): Grief; Conversion Disorder; Holistic Health. 